\title{
Potensi dan Peluang Pengembangan Hasil Hutan Bukan Kayu di KPHP Model Minas Tahura Provinsi Riau
}

\author{
Eni Suhesti, Hadinoto dan Eno Suwarno \\ Dosen Fakultas Kehutanan Universitas Lancang Kuning \\ JIn. Yos Sudarso Km. 8 Rumbai Pekanbaru Riau \\ Email:suhestieni@gmail.ac.id, hdinto@yahoo.co.id,dan enouwarno@gmail.com
}

\begin{abstract}
S
This study aims to identify the types of Non-Timber Forest Products (NTFPs) in the KPHPModelMinas Tahura area and analyze the development opportunities to diversify the income of the people around the forest. The research method is survey method, with object of forest area and community around forest. The data taken are primary data, ie vegetation types that have the potential to generate NTFPs and respondent profile data as well as their interests and desires to develop NTFPs. While the secondary data in the form of general conditions KPHP Model Minas Tahura and other data that support. The results of all data are analyzed descriptively. Result of survey and analysis of vegetation found 30 species at the level of trees, While at the pile level found 21 species, the level of sapling 16 species, and the level of seeds as many as 29 species. From all levels of vegetation growth, there are 21 species that potentially produce NTFPs with various functions and benefits, such as food, medicines, and industrial raw materials. The results of interviews and answers to questionnaires from community respondents around the forest, all respondents know NTFPs and are eager to develop various types of NTFPs in forest areas. It can be concluded that KPHP Model Minas Tahura area has the potential to develop NTFPs based on the availability of critical land for rehabilitation with various types of plants and the desire of surrounding communities to get involved in such activities.
\end{abstract}

Keywords: KPHP Model Minas Tahura; Mining opportunities; Non-Timber Forest Products (NTFPs);Potential

\section{PENDAHULUAN}

Kesatuan Pengelolaan Hutan

Produksi (KPHP) Model Minas TAHURA yang lokasinya berada pada tiga wilayah administratif Kabupaten/Kota, yaitu Kabupaten Kampar, Kabupaten Siak, dan Kota Pekanbaru merupakan salah satu KPHP yang saat ini dalam kondisi kritis dan menghawatirkan akibat perambahan, penebangan liar, kebakaran hutan, alih fungsi lahan secara illegal, dan permasalahanpermasalahan lainnya. Sebagai sebuah unit pengelola hutan di tingkat tapak, KPHP Model Minas TAHURA tentu akan berupaya untuk memulihkan kondisi demikian, sehingga tujuan pembentukan $\mathrm{KPH}$ yaitu untuk menyediakan wadah bagi terselenggaranya kegiatan 
pengelolaan hutan secara efisien dan lestari dapat terwujud.

Pengelolaan KPHP Model Minas TAHURA, sebagaimana pengelola hutan lainnya di Indonesia, tidak boleh terlepas dari amanat Undang-Undang No. 5 tahun 1967 tentang Pokok Kehutanan bahwa pengurusan hutan pada hakekatnya adalah untuk mendapatkan manfaat yang sebesar-besarnya secara serbaguna dan lestari baik secara langsung maupun tidak langsung, bagi kemakmuran masyarakat.

Demi terselenggaranya kegiatan pengelolaan hutan secara efisien dan lestari, pengelola KPHP Model Minas TAHURA seyogyanya melibatkan masyarakat sekitar hutan. Dengan pelibatan masyarakat tersebut, maka diharapkan masyarakat akan mendapatkan manfaat hari hutan sehingga akan timbul juga keinginan untuk ikut menjaga keberadaan hutan. Bentuk-bentuk pelibatan masyarakat dalam pengelolaan hutan akan sangat dipengaruhi oleh potensi yang dimiliki oleh hutan dan kesesuaian minat dan kebiasaan masyarakat di sekitar hutan tersebut. Untuk mengetahui potensi yang dimiliki oleh hutan diperlukan kegiatan inventarisasi. Salah satu kemungkinan pelibatan masyarakat dalam pengelolaan hutan adalah dalam pemanfaatan hasil hutan bukan kayu (HHBK). Pemanfaatan HHBK dari kawasan hutan oleh masyarakat sekitar hutan merupakan salah satu cara pengelola KPHP Model Minas TAHURA untuk memberikan akses kepada masyarakat sekitar hutan untuk mendapat manfaat dari hutan, tanpa merusak tegakan hutan. Akan tetapi, sebelum pemberian akses tersebut, diperlukan data-data jenis-jenis HHBK yang potensial untuk dimanfaatkan oleh masyarakat dan berpeluang untuk dikembangkan.

penelitian ini bertujuan untuk: 1) Mengidentifikasi jenis-jenis HHBK di kawasan KPHP Model Minas Tahura, 2) Menganalisis peluang pengembangan HHBK di kawasan KPHP Model Minas Tahura untuk diversifikasi pendapatan masyarakat sekitar hutan.

\section{METODE PENELITIAN}

Penelitian ini dilakukan di KPHP Model Minas Tahura. Waktu penelitian November 2016 - April 2017. Metode penelitian adalah dengan metode survey. Pengambilan data dilakukan terhadap 2 objek yaitu kawasan hutan dan masyarakat sekitar hutan. Data-data yang diambil secara langsung di 
lapangan terdiri atas :komposisi dan struktur vegetasi, kondisi eksisting lapangan, keinginan dan minat masyarakat untuk mengembangkan HHBK di sekitar kawasan KPHP Model Minas Tahura. Data sekunder dikumpulkan melalui studi literatur. Data sekunder merupakan data pendukung yang sangat penting dan dikumpulkan dari berbagai sumber antara lain : kondisi umum lokasi, monografi desa, buku teks, hasil-hasil penelitian, jumal penelitian, internet dan sumber lainnya

\section{Pengumpulan Data}

Pengumpulan data di lapangan adalah sebagai berikut

\section{a. Inventarisasi Potensi HHBK :}

1) Analisis Vegetasi di Kawasan TAHURA SSH

Untuk mendapatkan struktur dan komposisi dilakukan kegiatan analisis vegetasi dengan menggunakan metode jalur/garis berpetak. Panjang jalur 500 meter dengan dibagi menjadi 5 jalur yang masing-masing panjangnya 100 meter dan jarak antar jalur 50 meter. Cara pengambilan data seperti pada Gambar 1.

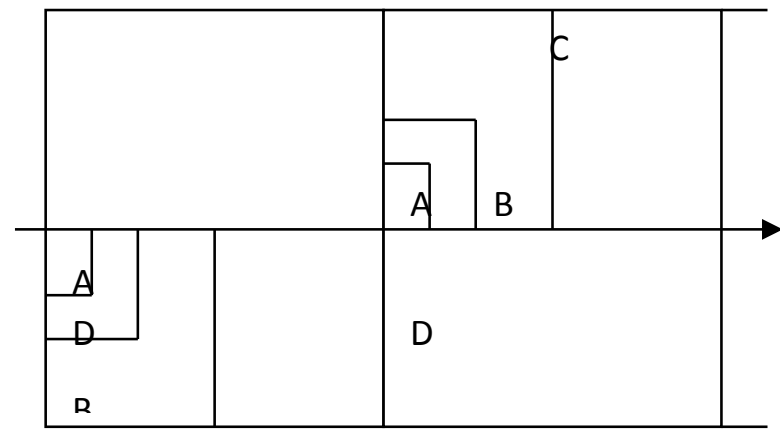

Gambar 1. Metode Pengambilan Data Dengan Cara Garis berpetak.

Keterangan :

Petak $A=$ ukuran $2 \mathrm{~m} \times 2 \mathrm{~m}$ untuk tingkat semai (seedling)

Petak $B=$ ukuran $5 \mathrm{~m} \times 5 \mathrm{~m}$ untuk tingkat pancang (sapling)

Petak $\mathrm{C}=$ ukuran $10 \mathrm{~m} \times 10 \mathrm{~m}$ untuk tingkat tiang (poles)

Petak $\mathrm{D}=$ ukuran $20 \mathrm{~m} \times 20 \mathrm{~m}$ Untuk tingkat pohon (trees)

2) Observasi kondisi kawasan

Sedangkan untuk data kondisi kawasan akan dilakukan observasi lapangan dengan mencatat beberapa hal antara lain : kondisi vegetasi, kondisi tutupan lahan dan, kondisi lahan/tanah

b. Peluang Pengembangan HHBK :

1) Pengambilan data dengan kuisioner 
Untuk mendapatkan data dalam rangka melihat peluang pengembangan HHBK dilakukan dengan cara memberikan daftar pertanyaan/kuisioner kepada masyarakat sekitar KPHP Minas Tahura (Desa Muara Fajar dan Minas Jaya). Pengambilan sampel dilakukan dengan cara acak (random sampling). Jumlah sampel yang akan diambil sebanyak 30 orang (15 orang@ desa)

2) Wawancara

Wawancara akan dilakukan kepada beberapa tokoh kunci, antara lain $\mathrm{KKPH}$ Model Minas Tahura, Kepala Desa Muara Fajar dan Minas Jaya

\section{Pengolahan dan Analisis Data}

\section{a. Potensi HHBK}

Data yang diperoleh dari lapangan akan dianalisis sebagai berikut:

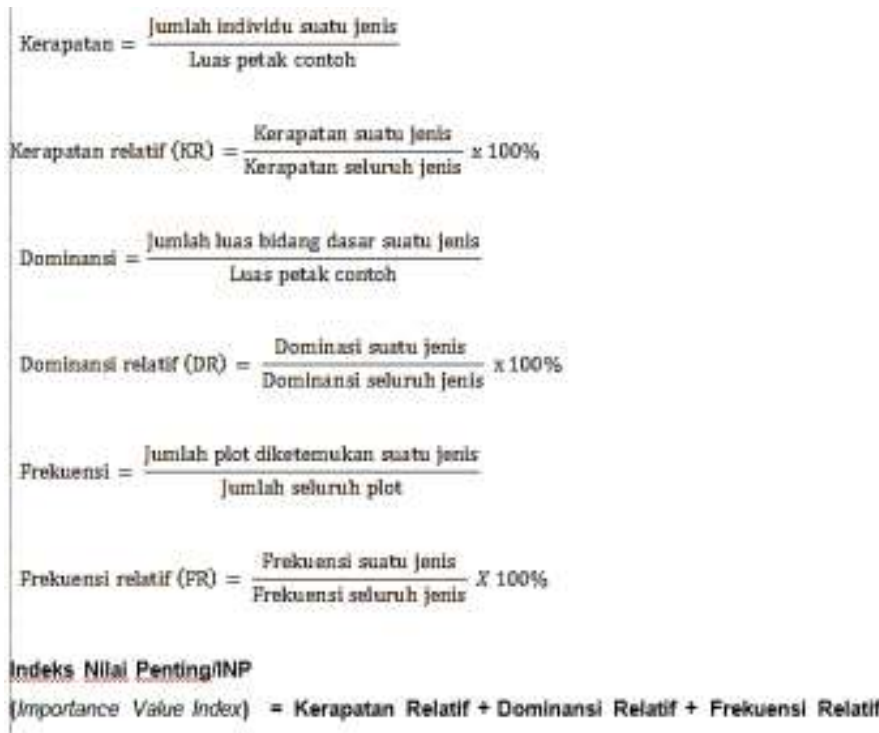

\section{b. Peluang Pengembangan HHBK}

Data hasil pengisian kuisioner akan direkapitulasi, ditabulasi dan dideskripsikan sesuai dengan tujuan yang ingin dicapai.

Hasil semua data tersebut di atas akan dianalisis secara deskriptif, yaitu penggambaran data yang diperoleh secara apa adanya, tanpa ada peng-generalisasian (Irianto 2007). Data akan digambarkan melalui tabel atau grafik.

\section{HASIL DAN PEMBAHASAN}

\section{Potensi Hasil Hutan Bukan Kayu di} dalam Kawasan KPHP MinasTahura

Hasil Hutan Bukan Kayu (HHBK) yang disurvey potensinya dalam penelitian ini adalah HHBK dari kelompok nabati (vegetasi) saja, sedangkan dari kelompok hewani tidak disurvey. Survey potensi HHBK di dalam kawasan KPHP Minas Tahura dilakukan dengan menggunakan metode kombinasi jalur berpetak. Jumlah plot pengamatan terdiri dari 11 plot atau seluas 0,44 $\mathrm{Ha}$ untuk masing-masing tingkat pertumbuhan vegetasi, yaitu tingkat pohon, tiang, pancang, dan semai. Data hasil survey tersebut dilampirkan di Lampiran 1. 
Jumlah tumbuhan di tingkat dominansi relatif dan indeks nilai penting pohon yang ditemukan pada 11 plot seperti pada Tabel 1. Sedangkan pada pengamatan tersebut, terdapat 30 jenis pohon dengan nilai kelimpahan dan tingkat tiang ditemukan 21 jenis, tingkat penguasaan masing-masing, yaitu pancang 16 jenis, dan tingkat semai keraparan relatif, frekuensi relatif,

Tabel 1. Jenis pohon dan nilai kelimpahan dan penguasaannya di KPHP Minas Tahura

\begin{tabular}{llcccc}
\hline No. & \multicolumn{1}{c}{ Nama Jenis } & $\begin{array}{c}\text { KR } \\
(\%)\end{array}$ & FR (\%) & DR (\%) & $\begin{array}{c}\text { Indeks Nilai } \\
\text { Penting (\%) }\end{array}$ \\
\hline 1 & $\begin{array}{l}\text { Artocarpus } \\
\text { champeden }\end{array}$ & 2.22 & 1.52 & 2.34 & 6.08 \\
\hline 2 & Artocarpus rigidus & 1.11 & 1.52 & 0.90 & 3.53 \\
\hline 3 & Artocarpus sp. & 2.22 & 1.52 & 2.73 & 6.47 \\
\hline 4 & $\begin{array}{l}\text { Calerya } \\
\text { arthopupurea }\end{array}$ & 1.11 & 1.52 & 1.09 & 3.71 \\
\hline 5 & Callophylum sp. & 1.11 & 1.52 & 0.71 & 3.33 \\
\hline 6 & Cinnamomum sp. & 8.89 & 7.58 & 6.51 & 22.98 \\
\hline 7 & Cratoxylon & 4.44 & 4.55 & 3.40 & 12.39 \\
\hline 8 & Dehorescen & 2.22 & 3.03 & 1.32 & 6.57 \\
\hline 9 & Dialium sp. & 1.11 & 1.52 & 1.11 & 3.73 \\
\hline 10 & Dillenia obovata & 4.44 & 4.55 & 4.16 & 13.15 \\
\hline 11 & Endospermum & 21.11 & 13.64 & 27.79 & 62.54 \\
\hline 12 & Guodenum & 4.44 & 3.03 & 3.82 & 11.30 \\
\hline 13 & Gluta renghas & 2.22 & 3.03 & 1.43 & 6.69 \\
\hline 14 & Hopea sangal & 1.11 & 1.52 & 1.99 & 4.62 \\
\hline 15 & Myristica sp. & 2.22 & 3.03 & 0.97 & 6.22 \\
\hline 16 & Nephelium sp. & 2.22 & 3.03 & 0.89 & 6.14 \\
\hline 17 & Ochanostachys & 3.33 & 4.55 & 1.59 & 9.46 \\
\hline 18 & Palaquium gutta & 6.67 & 6.06 & 4.16 & 16.89 \\
\hline 19 & Parashorea aptera & 1.11 & 1.52 & 2.23 & 4.86 \\
\hline 20 & Petungah sp. & 1.11 & 1.52 & 0.44 & 3.07 \\
\hline 21 & Polyanthia sp. & 1.11 & 1.52 & 0.46 & 3.08 \\
\hline 22 & Quercus sp. & 3.33 & 3.03 & 3.65 & 10.02 \\
\hline 23 & Santirya laevata & 1.11 & 1.52 & 0.75 & 3.38 \\
\hline 24 & Shorea parvifolia & 1.11 & 1.52 & 1.27 & 3.89 \\
\hline 25 & Shorea sp. & 1.11 & 1.52 & 0.48 & 3.10 \\
\hline 26 & Sloetia elongata & 4.44 & 6.06 & 3.61 & 29.70 \\
\hline 27 & Syzygium densiflora & 7.78 & 7.58 & 14.34 & \\
\hline & & & & & \\
\hline
\end{tabular}




\begin{tabular}{cccccc}
\hline No. & Nama Jenis & $\begin{array}{c}\text { KR } \\
(\%)\end{array}$ & FR (\%) & DR (\%) & $\begin{array}{c}\text { Indeks Nilai } \\
\text { Penting (\%) }\end{array}$ \\
\hline 28 & Tristaniopsis sp. & 2.22 & 3.03 & 3.40 & 8.65 \\
\hline 29 & Xylopia altissima & 2.22 & 3.03 & 1.85 & 7.10 \\
\hline 30 & Xylopia $s p$. & 1.11 & 1.52 & 0.61 & 3.24 \\
\hline & Jumlah & $\mathbf{1 0 0}$ & $\mathbf{1 0 0}$ & $\mathbf{1 0 0}$ & $\mathbf{3 0 0}$ \\
\hline
\end{tabular}

Sumber : Data Primer (2017)

Jenis vegetasi yang tercantum

pada Tabel 1 tersebut di atas tidak semua berpotensi menghasilkan HHBK yang dapat dimanfaatkan oleh masyarakat sekitar hutan. Oleh Karena itu, maka dilakukan lagi identifikasi jenisjenis yang berperan sebagai HHBK, berdasarkan literatur, keterangan pengelola hutan, dan masyarakat. Jenis-jenis vegetasi yang dapat dimanfaatkan sebagai HHBK di KPHP Minas Tahura dikelompokkan sesuai fungsinya, seperti pada Tabel 2 berikut ini.

Tabel 2. Jenis-Jenis Vegetasi Penghasil HHBK di KPHP Minas Tahura

\begin{tabular}{|c|c|c|c|c|}
\hline \multirow{2}{*}{ No } & \multirow{2}{*}{ Nama IImiah } & \multirow{2}{*}{$\begin{array}{l}\text { Nama } \\
\text { Lokal }\end{array}$} & \multicolumn{2}{|c|}{$\begin{array}{c}\text { Bagian Yang Dimanfaatkan dan } \\
\text { Kegunaan }\end{array}$} \\
\hline & & & $\begin{array}{l}\text { Bahan } \\
\text { Pangan }\end{array}$ & $\begin{array}{c}\text { Bahan Obat-Obatan } \\
\text { dan Industri }\end{array}$ \\
\hline 1 & $\begin{array}{l}\text { Arthocarpus } \\
\text { champeden }\end{array}$ & Cempedak & buah & Kulit batang \\
\hline 2 & Arthocarpus rigidus & Tempunik & Buah & \\
\hline 3 & Artocarpus sp. & $\begin{array}{l}\text { Nangka } \\
\text { Hutan }\end{array}$ & Buah & \\
\hline 4 & Callophylum sp. & Bintangur & - & Kulit batang (rabun) \\
\hline 5 & Cinnamomum sp. & Kayu Manis & $\begin{array}{l}\text { Kulit Batang } \\
\text { (bahan } \\
\text { syrup, } \\
\text { Bumbu } \\
\text { masakan) }\end{array}$ & $\begin{array}{l}\text { Kulit Batang (anti infeksi, } \\
\text { menurunkan gula darah, } \\
\text { menurunkan kolesterol) }\end{array}$ \\
\hline 6 & Dialium sp. & Kranji & Buah & $\begin{array}{l}\text { Buah(sariawan,diare, } \\
\text { gusi berdarah,kolesterol } \\
\text { jahat) }\end{array}$ \\
\hline 7 & Dillenia obovata & simpur & & Tanaman hias \\
\hline 8 & Garcinia atroviridis & $\begin{array}{l}\text { Asam } \\
\text { Kandis }\end{array}$ & $\begin{array}{l}\text { Buah } \\
\text { (penyedap } \\
\text { masakan) }\end{array}$ & $\begin{array}{l}\text { Daging buah, kulit } \\
\text { buah,kulit batang (anti } \\
\text { oksidan, rematik, radang } \\
\text { telinga, hyper tensi, } \\
\text { radang gusi, mengurangi } \\
\text { kolesterol jahat) }\end{array}$ \\
\hline 9 & Gluta renghas & Rengas & $\begin{array}{l}\text { Daun muda } \\
\text { (lalapan) }\end{array}$ & $\begin{array}{l}\text { Getah (bahan baku } \\
\text { pernis) }\end{array}$ \\
\hline
\end{tabular}




\begin{tabular}{|c|c|c|c|c|}
\hline \multirow{2}{*}{ No } & \multirow{2}{*}{ Nama IImiah } & \multirow{2}{*}{$\begin{array}{l}\text { Nama } \\
\text { Lokal }\end{array}$} & \multicolumn{2}{|c|}{$\begin{array}{l}\text { Bagian Yang Dimanfaatkan dan } \\
\text { Kegunaan }\end{array}$} \\
\hline & & & $\begin{array}{l}\text { Bahan } \\
\text { Pangan }\end{array}$ & $\begin{array}{c}\text { Bahan Obat-Obatan } \\
\text { dan Industri }\end{array}$ \\
\hline 10 & Nephelium sp. & $\begin{array}{l}\text { Rambutan } \\
\text { Hutan }\end{array}$ & $\begin{array}{l}\text { Buah } \\
\text { (makanan } \\
\text { satwa) }\end{array}$ & \\
\hline 11 & $\begin{array}{l}\text { Ochanostachys } \\
\text { amentacea }\end{array}$ & Petaling & & Daun (obat demam) \\
\hline 12 & Palaquium gutta & Balam & & $\begin{array}{l}\text { Daun dan Batang } \\
\text { (getahnya untuk bahan } \\
\text { baku lapisan bola golf, } \\
\text { lapisan pembuat gigi } \\
\text { palsu, lapisan gips } \\
\text { pembalut tulang) }\end{array}$ \\
\hline 13 & Tristaniopsis sp. & Pelawan & & $\begin{array}{l}\text { Daun, kulit batang, } \\
\text { akar,air batang (sakit } \\
\text { perut, lever, maag, } \\
\text { penguat stamina) }\end{array}$ \\
\hline 14 & Alstonia scholaris & Pulai & & $\begin{array}{l}\text { Daun (obat demam), } \\
\text { getah (bahan campuran } \\
\text { pelitur) }\end{array}$ \\
\hline 15 & Canarium sp & Kenari & $\begin{array}{l}\text { Buah } \\
\text { (dimakan) }\end{array}$ & \\
\hline 16 & Macaranga sp & Mahang & & $\begin{array}{l}\text { Getah Batang (sariawan, } \\
\text { tetes mata) }\end{array}$ \\
\hline 17 & $\begin{array}{l}\text { Aquilaria } \\
\text { malaccensis }\end{array}$ & Gaharu & & $\begin{array}{l}\text { Batang, daun (Bahan } \\
\text { baku industry dan obat- } \\
\text { obatan) }\end{array}$ \\
\hline 18 & $\begin{array}{l}\text { Baccaurea } \\
\text { macrocarpa }\end{array}$ & Tampui & $\begin{array}{l}\text { Buah } \\
\text { (langsung } \\
\text { dimakan) }\end{array}$ & \\
\hline 19 & Barringtonia sp. & Putat & $\begin{array}{l}\text { Daun (untuk } \\
\text { sayuran) }\end{array}$ & \\
\hline 20 & $\begin{array}{l}\text { Scorodocarpus } \\
\text { borneensis }\end{array}$ & Kulim & $\begin{array}{l}\text { Buah, daun } \\
\text { (sayuran) }\end{array}$ & \\
\hline 21 & Pometia sp. & $\begin{array}{l}\text { Kasai, } \\
\text { matoa }\end{array}$ & $\begin{array}{l}\text { Buah } \\
\text { (dimakan } \\
\text { langsung) }\end{array}$ & $\begin{array}{l}\text { Kulit kayu (luka), daun } \\
\text { dan kulit kayu (demam, } \\
\text { menghitamkan } \\
\text { rambut,influenza, } \\
\text { disentri) }\end{array}$ \\
\hline
\end{tabular}

Potensi HHBK di KPHP Minas kukuran (Schizophyllum commune) Tahura yang tidak termasuk di dalam (Gambar 2). Rotan ditemukan dalam plot pengamatan, tetapi ditemui saat jumlah yang relatif sedikit, akan tetapi penelitian adalah rotan dan jamur keberadaannya menunjukkan bahwa di 
dalam kawasan Tahura SSH dapat dikembangkan jenis rotan tersebut, dan berpeluang sebagai salah satu HHBK yang potensial untuk dikembangkan di masa yang akan datang. Demikian juga dengan jamur, saat penelitian jumlah jamur yang ditemui hanya dalam jumlah sedikit, Karena pada saat penelitian belum memasuki musim hujan. Jamur tersebut dapat dikembangkan sebagai salah satu HHBK yang banyak penggemarnya di tengah masyarakat dan harga pasarannya cukup tinggi, yaitu berkisar antara Rp. 60.000 Rp.75.000,-(data hasil survey peneliti di pasar tradisional). Selain jamur kukuran, dapat dikembangkan juga jenis-jenis jamur lain, seperti jamur kuping, mengingat kondisi di dalam kawasan hutan yang lembab dan banyak kayu dari pohon yang tumbang atau ranting yang lapuk yang merupakan habitat yang sesuai untu pertumbuhan jamur tersebut.

\section{Peluang Pengembangan HHBK Bersama Masyarakat Sekitar Tahura Sutan Syarif Hsayim}

Dari beberapa kasus di Indonesia dalam mengelola kawasan hutan, terutama untuk merehabilitasi kawasan yang kristis telah melibatkan masyarakat sekitar hutan, misalnya di Tahura Wan Abdul Rachman di Lampung (Riani 2014), di Taman Wisata Alam Gunung Selok Cilacap (Sumarhani 2015), dan di beberapa daerah lainnya. Dari kasuskasus tersebut diketahui bahwa luasan kawasan yang kritis berkurang, keanekaragaman jenis hayati meningkat, dan pendapatan masyarakat yang terlibat juga meningkat. Pelibatan masyarakat dalam pengelolaan hutan seyogyanya memang bertujuan untuk menjaga kelestarian hutan dan meningkatkan

kesejahteraan masyarakat. Kerjasama antara pengelola hutan dan masyarakat dapat dilakukan dengan berbagai macam pola, misalnya dengan memberi akses kepada masyarakat untuk memanfaatkan dan mengembangkan HHBK di dalam kawasan hutan, tetapi dengan mematuhi segala ketentuan yang berlaku. Pola lain yang dalam pemanfaatan dan pengembangan HHBK adalah dengan sistem agroforestry, yaitu kegiatan budidaya tanaman secara campuran antara tanaman kehutanan (pohon-pohonan) dengan tanaman pertanian.

Hasil wawancara terhadap masyarakat sekitar Tahura SSH maupun jawaban kuisioner yang diberikan 
kepada responden menggambarkan bahwa masyarakat berkeinginan untuk mengembangkan HHBK sebagai upaya untuk diversifikasi pendapatan mereka. Hal tersebut sejalan dengan yang disampaikan oleh Njurumana dan Butarbutar (2008) bahwa salah satu alternatif untuk meningkatkan diversifikasi pendapatan masyarakat adalah dengan pengembangan HHBK melalui agroforestry.

Masyarakat yang bermukim di sekitar KPHP Minas Tahura yang yang menjadi responden dalam penelitian ini sebagian besar bekerja sebagai petani, yang menggarap lahan pekarangan dan kebun dengan berbagai tanaman palawija yang berpenghasilan per bulan antara Rp. 800.000 - Rp. 8.000.000,(Lampiran 1). Semua responden menjawab mengetahui tentang $\mathrm{HHBK}$ dan berkeinginan untuk mengembangkannya di dalam kawasan hutan. Jenis-jenis HHBK yang ingin dikembangkan oleh responden beragam, mulai dari tanaman karet (Hevea brasiliensis) sampai buahbuahan dan tanaman palawija (semusim). Dari wawancara, masyarakat juga bersedia bekerjasama untuk ikut menanami kawasan hutan yang kritis dengan tanaman kehutanan.
Berdasarkan informasi dari pihak pengelola Tahura SSH dan pengamatan tim peneliti, kondisi Tahura SSH sudah mengalami pengurangan luas yang cukup berarti, yaitu dari luas keseluruhan kawasan hutan sekitar $6.172 \mathrm{Ha}$ (SK Menhut No. 348/KPTS/II/1999), yang masih berhutan saat ini hanya tinggal $2.087 \mathrm{Ha}$ saja dan sebagian kawasan sudah berada dalam kondisi kritis.

Dengan masih banyaknya kawasan hutan yang dalam kondisi kritis yang sangat perlu untuk direhabilitasi di Tahura SSH dan adanya keinginan dari masyarakat sekitar untuk ikut terlibat dalam menanami kawasan hutan yang kritis tersebut, maka peluang pengembangan HHBK dengan pola agroforestry masih sangat terbuka. Akan tetapi untuk melaksanakan kegiatan tersebut diperlukan kesediaan dan komitmen dari pihak pengelola Tahura SSH, yaitu pengelola KPHP Minas Tahura. Apabila sudah ada komitmen dari kedua belah pihak untuk mengembangkan HHBK dengan pola agroforestry dalam merehabilitasi lahan kritis di Tahura SSH, maka selanjutnya perlu dikaji kesesuaian lahan dengan jenis tanaman yang akan dikembangkan 
dan pola agroforestry yang paling optimal.

\section{KESIMPULAN DAN SARAN}

Kesimpulan dari penelitian ini adalah

sebagai berikut :

1. Hasil Hutan Bukan Kayu yang berupa vegetasi pada tingkat pohon, tiang, pancang, dan semai yang teridentifikasi di KPHP Model Minas Tahura berjumlah 21 jenis dengan tingkat keragaman dan dominasi yang berbeda-beda serta manfaat yang berbeda-beda pula

2. Kawasan KPHP Model Minas Tahura berpotensi untuk pengembangan Hasil Hutan Bukan Kayu berdasarkan ketersediaan lahan kritis untuk direhabilitasi dengan beragam jenis tanaman dan keinginan masyarakat sekitar untuk ikut terlibat kegiatan tersebut.

Saran dari hasil penelitian ini antara lain adalah :

1. Untuk pengembangan $\mathrm{HHBK}$ di kawasan KPHP Model Minas Tahura sebagai upaya merehabilitasi kawasan kritis dengan melibatkan masyarakat sekitar, diperlukan keinginan dan komitmen dari pihak pengelola dan masyarakat yang dilaksanakan dengan mekanisme legal formal.

2. Masih diperlukan kajian-kajian tentang kesesuaian lahan dengan jenis-jenis komoditas yang akan ditanam di kawasan KPHP Model Minas Tahura dalam rangka merahabilitasi lahan kritis, meningkatkan keanekaragaman hayati, serta dampak kegiatan terhadap kawasan hutan dan masyarakat.

\section{DAFTAR PUSTAKA}

BP2SDMK Dephut. 2013. Jenis HHBK unggulan nasional. bp2sdmk.dephut.go.id. Diakses tanggal 28 April 2015.

Fauzi H. Peranan hasil hutan non kayu terhadap pendapatan masyarakat. Jurnal Hutan Tropis Borneo No.23 September 2008. Hal: 73 -82.

Gusmailina. 2010. Peningkatan mutu pada gaharu kualitas rendah. Jurnal Penelitian Hasil Hutan. Vol. 28 No.3. September 2010. Hal: 291-303.

Kendek CN, Tasirin JS, Kainde RP, dan Kalangi JI. 2015. Pemanfaatan hasil hutan bukan kayu oleh masyarakat sekitar hutan Desa Minanga III Kabupaten Minahasa Tenggara. Ejournal. unsrat.ac.id 
/index.php/cocos/ article/download. Diakses tanggal 23 April 2015.

Mayrowani H dan Ashari. 2011. Pengembangan agroforestry untuk mendukung ketahanan pangan dan pemberdayaan petani sekitar hutan. Forum Penelitian Agro Ekonomi Vol.29 No.2 Desember 2011. Hal: $83-98$.

Moko H. 2008. Menggalakkan hasil hutan bukan kayu sebagai produk unggulan. Informasi Teknis Vol.6 No. 2. September 2008. Hal : 1 6.

Njurumana GND dan Butarbutat T. 2008. Prospek pengembangan hasil hutan bukan kayu berbasis agroforestry untuk peningkatan dan diversifikasi pendapatan masyarakat di Timor Barat. Info Hutan Vol.V No. 1. 2008. Hal : 53 -62 .

Permenhut RI No P.35/Menhut-II/2007. Tentang Hasil Hutan Bukan Kayu

Permenhut RI No P.19/Menhut-II/2009. Tentang Strategi Pengembangan Hasil Hutan Bukan Kayu Nasional

Sudarmalik, Rochmayanto P, dan Purnomo. 2006. Peranan hasil hutan bukan kayu (HHBK) di Riau dan Sumbar. Prosiding Seminar Hasil Litbang Hasil Hutan 2006. Hal : $199-219$.

Undang-Undang No.5 Tahun 1967. Tentang Ketentuan-Ketentuan Pokok Kehutanan

Wahyuningsih $\mathrm{MH}$, Wulandari $\mathrm{C}$, Hernawati S. 2014. Analisis keyakan usaha berbasis hasil hutan bukan kayu ekosistem mangrove di
Desa Margasari Lampung Timur. Jurnal Sylva Lestari Vol.2 No.2 Pebruari 2014. Hal: 41-48.

Zulaifah S. 2006. Pemanfaatan hutan bersama masyarakat untuk pengembangan kawasan hutan Regaloh di Kabupaten Pati Jawa Tengah. [Thesis]. Semarang: Program studi Magister Teknik Pembangunan Wilayah dan Kota Program Pascasarjana Universitas Diponegoro. 